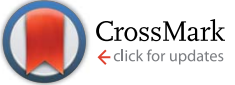

Cite this: RSC Adv., 2017, 7, 344

Received 20th October 2016 Accepted 16th November 2016

DOI: 10.1039/c6ra25557d

www.rsc.org/advances

\section{A novel synthetic approach to poly(hydrosiloxane)s via hydrolytic oxidation of primary organosilanes with a AuNPs-stabilized Pickering interfacial catalyst $\uparrow$}

\begin{abstract}
Ravi Shankar, ${ }^{*}$ Bhawana Jangir and Asmita Sharma
The triblock copolymer, $\mathrm{PiBA}_{20}-b-\mathrm{PDMS}_{75}-b-\mathrm{PiBA}_{20}$ (PiBA $=$ polyisobornylacrylate, $\mathrm{PDMS}=$ polydimethylsiloxane), 1 is employed as an amphiphilic scaffold for surface functionalization of AuNPs of 10-15 nm size in chloroform. In water-chloroform biphasic medium, the AuNPs form a randomly close packed assembly at the interface and remain stable for several months under ambient conditions. The interfacially stabilized AuNPs act as a selective and recyclable catalyst for the hydrolytic oxidation of primary organosilanes, $\mathrm{RSiH}_{3}$ and offer a promising route for high yield synthesis of poly(alkyl/ arylhydrosiloxane)s $\mathrm{H}_{2} \mathrm{RSiO}[\mathrm{RHSiO}]_{n} \mathrm{SiRH}_{2}, 2-6\left[\mathrm{R}=\mathrm{Ph}\right.$ (2), n-hexyl (3), cyclo-hexyl (4), $\mathrm{Et}_{3} \mathrm{SiCH}_{2} \mathrm{CH}_{2}$ (5), $\left.\mathrm{PhMe}_{2} \mathrm{SiCH}_{2} \mathrm{CH}_{2}(6)\right]$.
\end{abstract}

\section{Introduction}

Polysiloxanes, $\left[\mathrm{RR}^{1} \mathrm{SiO}\right]_{n}\left(\mathrm{R}, \mathrm{R}^{1}=\right.$ alkyl or aryl $)$ are among the well-known synthetic polymers and differ in many respects from other inorganic polymers due to their unique properties associated with a flexible $\mathrm{Si}-\mathrm{O}-\mathrm{Si}$ backbone. ${ }^{1}$ As a result, these polymers find widespread applications in industry and modern technology. The classical synthetic approach to polysiloxanes involves acid or base-catalyzed hydrolysis and condensation of chloro-/alkoxy-substituted organosilane monomers. ${ }^{2}$ However, a major limitation of this approach arises from the sensitivity of the $\mathrm{Si}-\mathrm{O}-\mathrm{Si}$ bond to $\mathrm{pH}$ conditions and formation of undesired side products due to cleavage or redistribution/disproportionation of the siloxane framework are often observed. The advent of anionic/cationic ring opening polymerization of cyclo-siloxanes has provided a great deal of impetus in synthetic chemistry of high molecular weight polysiloxanes and its scope to construct block copolymers of varying compositions has been well documented., ${ }^{1,3}$ In recent years, considerable attention has been devoted to develop catalytic routes to siloxane frameworks with well-defined molecular weight and control over dimensionality. ${ }^{4}$ In this context, Lewis acid catalysts such as $\mathrm{B}\left(\mathrm{C}_{6} \mathrm{~F}_{5}\right)_{3}$, $\mathrm{BiCl}_{3}, \mathrm{Sc}(\mathrm{OTf})_{3}$, etc. have shown promise in terms of their selectivity for various functional group transformation and formation of $\mathrm{Si}-\mathrm{O}-\mathrm{Si}$ bonds under non-hydrolytic conditions. These studies are primarily driven by an impetus to expand the

Department of Chemistry, Indian Institute of Technology, Hauz Khas, New Delhi-110016, India. E-mail: shankar@chemistry.iitd.ac.in

$\dagger$ Electronic supplementary information (ESI) available. See DOI: $10.1039 / \mathrm{c} 6 \mathrm{ra} 25557 \mathrm{~d}$ library of functional synthons for the development of new siloxane-based materials. Several metal-based heterogeneous and homogeneous catalysts have been investigated for hydrolytic oxidation of $\mathrm{Si}-\mathrm{H}$ bonds in organosilanes. ${ }^{5}$ However, these catalysts often lack selectivity as the reactions are accompanied by the formation of a mixture of silanols, disiloxanes and siloxane oligomers. Recent studies have shown that gold nanoparticles on various solid supports are excellent heterogeneous catalysts for selective hydrolytic oxidation of tertiary organosilanes, $\mathrm{R}_{3} \mathrm{SiH}$ to afford exclusive formation of organosilanols with the elimination of dihydrogen as the byproduct. ${ }^{6}$

Poly(hydromethylsiloxane), $[\mathrm{Me}(\mathrm{H}) \mathrm{SiO}]_{n}$ (abbreviated as PMHS) has attracted considerable attention in view of the presence of $\mathrm{Si}-\mathrm{H}$ groups in the repeat unit. Hemery et al. have reported the synthesis of high molecular weight PMHS by cationic ring opening polymerization of 1,3,5,7-tetramethylcyclotetrasiloxane in aqueous emulsion using dodecylbenzenesulfonic acid and $\mathrm{C}_{12} \mathrm{H}_{25}\left(\mathrm{OCH}_{2} \mathrm{CH}_{2}\right)_{23} \mathrm{OH}$ (Brij35) as emulsifying agents. ${ }^{7}$ The presence of $\mathrm{Si}-\mathrm{H}$ groups in PMHS offers opportunity for chemical modification and incorporation of appended functional moieties on siloxane backbone by hydrosilylation, dehydrocoupling or click reactions. ${ }^{8}$ The functional groups endow these polymers with interesting physico-chemical properties and serve as scaffolds in the synthesis of Noble metal nanoparticles. The reducing property of PMHS has also been utilized for the reduction of a variety of organic substrates. ${ }^{9}$

The organization of colloidal metal/metal oxide particles at liquid-liquid interface, a phenomenon first described by Pickering, has emerged as an active area of research in catalysis. ${ }^{\mathbf{1 0}}$ For example, the entrapment and stabilization of catalytically active nano/colloidal particles $\left(\right.$ e.g. $\left.\mathrm{Pd}, \mathrm{SiO}_{2}\right)$ at the interface has 
been employed as an alternative to classical methods for chemical transformation of organic substrates and biomass refining: ${ }^{11}$ The energy $(\Delta E)$ of nanoparticles at the interface is governed by nature of the biphasic medium, wettability of the nanoparticle surface and effective radius of nanoparticles, as illustrated in the following equation:

$$
\Delta E=-\pi(d / 2)^{2} \gamma_{\mathrm{w} / \mathrm{o}}(1 \pm \cos \theta)^{2}
$$

where $\gamma_{\mathrm{w} / \mathrm{o}}$ is the interfacial tension between water and oil, $d$ the particle diameter, and $\theta$ the contact angle of particles at the interface.

The study described herein relates to the formation of a selfassembly of AuNPs at water-chloroform interface and its application as a selective Pickering catalyst for the synthesis of poly(alkyl/arylhydrosiloxane)s, $\mathrm{H}_{2} \mathrm{RSiO}[\mathrm{RHSiO}]_{n} \mathrm{SiRH}_{2}[\mathrm{R}=\mathrm{Ph}$ (2), n-hexyl (3), cyclo-hexyl (4), $\mathrm{Et}_{3} \mathrm{SiCH}_{2} \mathrm{CH}_{2}$ (5), $\mathrm{PhMe}_{2} \mathrm{SiCH}_{2}$ $\left.\mathrm{CH}_{2}(6)\right]$. The formation of the Pickering catalyst is achieved by surface decoration of AuNPs with amphiphilic block copolymer, $\mathrm{PiBA}_{20}-b-\mathrm{PDMS}_{75}-b-\mathrm{PiBA}_{20}$ (PiBA = polyisobornylacrylate, PDMS $=$ polydimethylsiloxane), $\mathbf{1}$.

\section{Results and discussion}

The block copolymer, $\mathrm{PiBA}_{20}-b-\mathrm{PDMS}_{75}-b-\mathrm{PiBA}_{20}$ (1) used for surface functionalization of AuNPs was synthesized by following atom transfer radical polymerization (ATRP) ${ }^{\mathbf{1 2}}$ of isobornylacrylate (iBA) monomer using difunctional macroinitiator, (2-bromoisobutyrate terminal-PDMS), copper bromide $(\mathrm{CuBr})$ and $N, N, N^{\prime}, N^{\prime \prime}, N^{\prime \prime}$-pentamethyldiethylenetriamine
(PMDETA) as complexing ligand (Scheme 1). The onset of polymerization was indicated by increase in viscosity of the solution. The overlaid SEC traces (Fig. S1 $\dagger$ ) of the aliquots at different time intervals reveal a progressive shift towards lower elution time (higher molar mass) compared to the PDMSmacroinitiator. An analysis of number average molecular weight $\left(M_{\mathrm{n}}\right)$ as a function of percentage conversion of the monomer (obtained from ${ }^{1} \mathrm{H}$ NMR data) shows a linear plot (Fig. S2 $\dagger$ ), suggesting that the initiation rate is sufficiently fast relative to propagation and termination is maintained at low level. This is further supported by a decrease in the value of polydispersity index from 2.0 to 1.12 as the polymerization progressed. In the ${ }^{1} \mathrm{H}$ NMR spectrum (Fig. S3 $\dagger$ ) the resonance at $\delta 1.9$ due to terminal $\left(\mathrm{CH}_{3}\right)_{2} \mathrm{CBr}$ groups of the difunctional macroinitiator is completely absent, suggesting the efficacy of each individual initiating site during polymerization reaction. The detailed synthetic procedure and spectroscopic characterization of $\mathbf{1}$ is described in the experimental section. An examination of gel permeation chromatographic data reveals $M_{\mathrm{n}}=$ $12570 \mathrm{~g} \mathrm{~mol}^{-1}$ and PDI $=1.12$. The assignments of complex ${ }^{1} \mathrm{H}$ NMR signals of 1 are made by comparison with those reported for poly(isobornylacrylate). ${ }^{13}$ The $\mathrm{Me}_{2} \mathrm{Si}(\delta$ 0.06) and $\mathrm{CH}$-isobornyl ( $\delta$ 4.25) protons associated with PDMS and PiBA segments appear in the intensity ratio of $1.8: 1$ and is consistent with the composition of the polymer. The ${ }^{29} \mathrm{Si}$ NMR spectrum reveals a single resonance at $\delta-21.9$ analogous to that observed in poly(dimethylsiloxane). The FT-IR spectrum in the solid state exhibits strong peaks at 1726, 1260 and $1089 \mathrm{~cm}^{-1}$ due to $\mathrm{C}=\mathrm{O}$ (ester), $\mathrm{Si}-\mathrm{Me}$ and $\mathrm{Si}-\mathrm{O}-\mathrm{Si}$ groups respectively. Thermo gravimetric analysis (TGA) and differential scanning<smiles>CC(C)(Br)C(=O)Br</smiles><smiles>CC(C)(Br)C(=O)OCCOCCC[Si](C)(C)O[Si](C)(C)O[Si](C)(C)CCCOCCOC(=O)C(C)(C)Br</smiles>

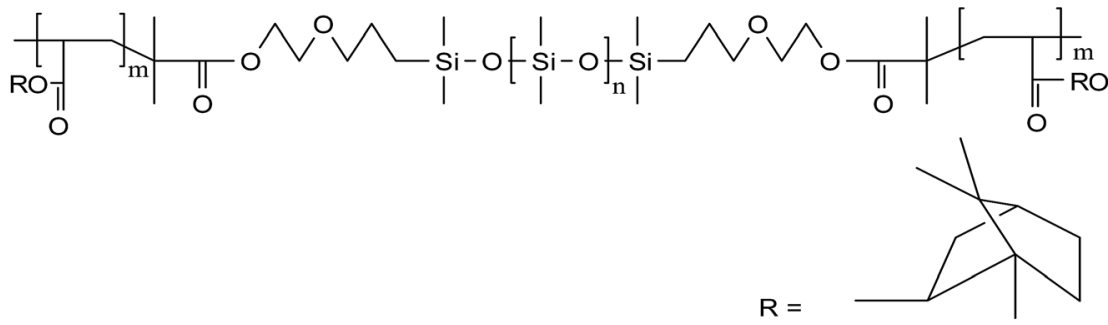

(i) $\mathrm{Et}_{3} \mathrm{~N}, \mathrm{THF}, \mathrm{RT}, 20 \mathrm{~h}$ (ii) iBA, CuBr, PMDETA, Toluene, $80^{\circ} \mathrm{C}, 4-5 \mathrm{~h}$ 
calorimetric (DSC) studies reveal that the polymer is thermally stable upto $280^{\circ} \mathrm{C}$ and exhibits glass transition temperature $\left(T_{\mathrm{g}}\right)$ of PiBA segment at $85{ }^{\circ} \mathrm{C}$. The PDMS segment could not be analysed by DSC due to temperature constraint of the available instrument. The glass transition temperature of PiBA segment in $\mathbf{1}$ is significantly lowered as compared to that of poly(isobornylacrylate) homopolymer $\left(94^{\circ} \mathrm{C}\right)^{\mathbf{1 4}}$ and the phenomenon likely arises from phase mixing of the PDMS and PiBA segments or configurational effects of the polymer chain. ${ }^{15}$

\section{Synthesis of AuNPs-stabilized Pickering interfacial catalyst in water-chloroform biphasic medium}

For the synthesis of Pickering interfacial catalyst, the initial step involves the reduction of hydrogen tetrachloroaurate(III) trihydrate in chloroform with triethylsilane ${ }^{\mathbf{1 6}}$ under ultrasonication in presence of polymer $\mathbf{1}$ as the stabilizing matrix. The formation of AuNPs is evident by a gradual colour change of the solution from yellow to purple within 5-10 minutes. The solution was allowed to attain equilibrium for $24 \mathrm{~h}$ under ambient conditions and used for further analysis. The UV-Vis spectrum of the colloidal suspension of AuNPs exhibits surface plasmon resonance at $540 \mathrm{~nm}$ along with a shoulder at $650 \mathrm{~nm}$ (Fig. 1). The observed spectral profile is suggestive of polydispersed nature of AuNPs. ${ }^{17}$ The plasmonic band does not show perceptible change even after a month suggesting that AuNPs are well passivated by the polymer matrix. Transmission electron microscopic (TEM) study was performed by depositing one drop of the solution on a carbon-coated copper grid. The TEM image shown in Fig. 1 is typical of that found over the entire grid and reveals the formation of polydispersed AuNPs of 10$15 \mathrm{~nm}$ size domain. Under high magnification, the TEM image

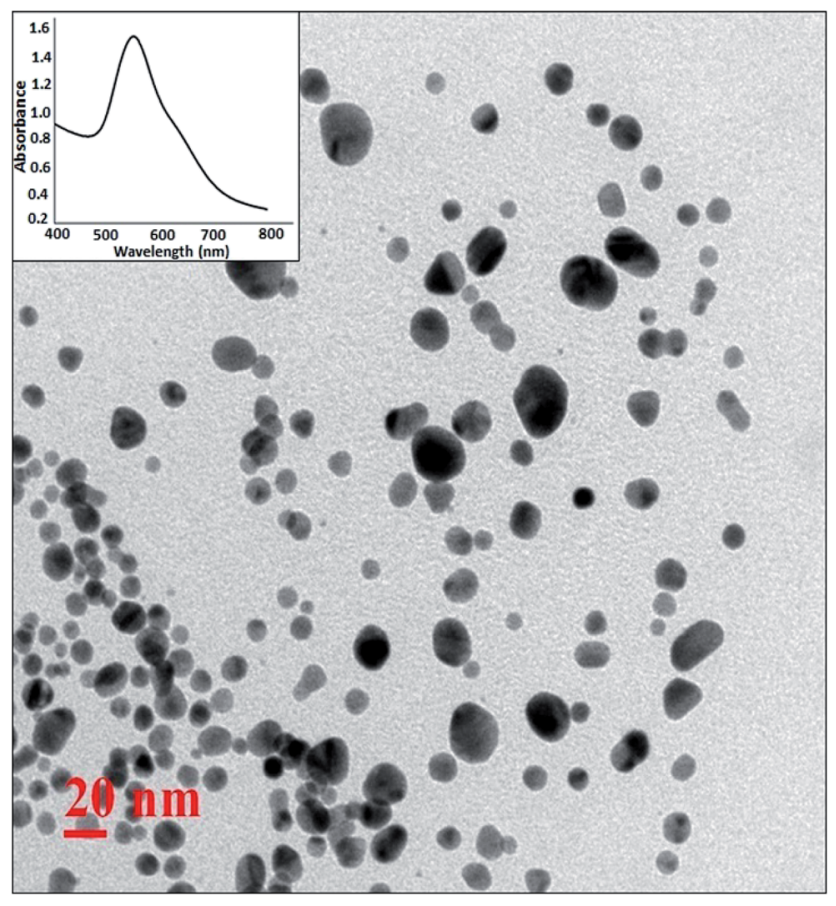

Fig. 1 HRTEM image of AuNPs in chloroform. identifies well resolved crystal lattice fringes featuring fcc gold (111) plane with a $0.236 \mathrm{~nm} d$ spacing between the adjacent lattice planes (Fig. S4†). The corresponding selected area electron diffraction (SAED) pattern confirms their polycrystalline nature (Fig. S5 $\dagger$ ). In subsequent step, addition of deionized water $(1.0 \mathrm{~mL})$ to a stirred colloidal suspension of AuNPs in chloroform (4.0 mL, $0.02 \mathrm{wt} \% \mathrm{Au})$ under ambient conditions results in entrapment of the AuNPs at the water-chloroform interface, while the organic layer becomes colourless within 30 minutes (Fig. 2). The interfacially stabilized polymer-AuNP assembly is hereafter referred as [Au]. It is noteworthy to mention that optimization of AuNP concentration ( $0.1 \mathrm{wt} \%)$ and water-chloroform volume ratio $(1: 1)$ affords the formation of a sheet like structure at the interface (Fig. 2). The AuNPs thus formed exhibit metallic lustre when light is passed into the sample. The HRTEM micrograph of [Au] is shown in Fig. 2. The result reveals an aggregation of individual nanoparticles that are not densely packed and do not show long-range order possibly because of the broad size and shape distribution. The plasmonic resonance appears at $\lambda_{\max }=540 \mathrm{~nm}$ and extends in the near IR region. The stability of the nanoparticles is not affected by changing the organic medium such as $\mathrm{CH}_{2} \mathrm{Cl}_{2}$, THF and toluene. Nevertheless, surface tethering of AuNPs by PiBA homopolymer does not favour the self-assembly process at water-chloroform interface and provides a basis to infer that organization of AuNPs at the interface is primarily driven by amphiphilic character of polymer 1. The results find analogy with an earlier report by Wang et al. The authors have demonstrated that organization of AuNPs at water-toluene interface is primarily governed by surface functionalization of AuNPs with amphiphilic 2-bromo-2-methyl-propionate terminated long chain thiolate groups while the size of nanoparticles does not affect this phenomenon significantly. ${ }^{10}$

\section{Synthesis and characterization of poly(hydrophenylsiloxane),} 2 using Pickering interfacial catalyst, [Au]

As a case study, phenylsilane was taken as a model substrate to study the hydrolytic oxidation of the $\mathrm{Si}-\mathrm{H}$ groups. The reaction was performed with $0.02 \mathrm{wt} \%$ of the [Au] catalyst at $80^{\circ} \mathrm{C}$ and monitored at different time intervals by ${ }^{1} \mathrm{H}$ NMR spectroscopy (Fig. 3). As the reaction progresses, a new resonance at $\delta 5.1$ appears in lieu of the signal at $\delta 4.1$ associated with phenylsilane. The former value is typical of $\mathrm{PhHSiO} / \mathrm{H}_{2} \mathrm{PhSiO}$ units ${ }^{18}$ suggesting the onset of hydrolytic oxidation of the precursor. The GC-MS spectrum (Fig. S6†) of the sample obtained after $2 \mathrm{~h}$ of the reaction identifies linear siloxanes of compositions, $\mathrm{H}_{2} \mathrm{PhSiOSiPh}(\mathrm{H})(\mathrm{OH})(\mathbf{A}) \mathrm{m} / z=245 ;[\mathrm{M}-\mathrm{H}], \mathrm{H}_{2} \mathrm{PhSiO}$ $\left[\mathrm{PhHSiO}_{\mathrm{SiPhH}_{2}}\right.$ (B) $m / z=351 ;[\mathrm{M}-\mathrm{H}]$ and $\mathrm{H}_{2} \mathrm{PhSiO}$ $\left[\mathrm{PhHSiO}_{2} \mathrm{SiPhH}_{2}(\mathbf{C})(\mathrm{m} / z=474)\right.$ in $3: 4: 1$ ratio. The signal due to the $\mathrm{Si}-\mathrm{H}$ protons of phenylsilane disappears after 9$10 \mathrm{~h}$. A usual work up (see Experimental section) of the reaction mixture affords the isolation of $\mathrm{H}_{2} \mathrm{PhSiO}[\mathrm{PhHSiO}]_{n}$ $\mathrm{SiPhH}_{2}, 2$ as viscous oil with $M_{\mathrm{w}}=1.5 \times 10^{3}$ and $\mathrm{PDI}=1.4$ as evident from gel permeation chromatography. In the ${ }^{1} \mathrm{H}$ NMR spectrum, the integral intensity of $\mathrm{Si}-\mathrm{Ph}$ and $\mathrm{Si}-H$ signals in $5: 1$ ratio is in conformity with the composition of the 


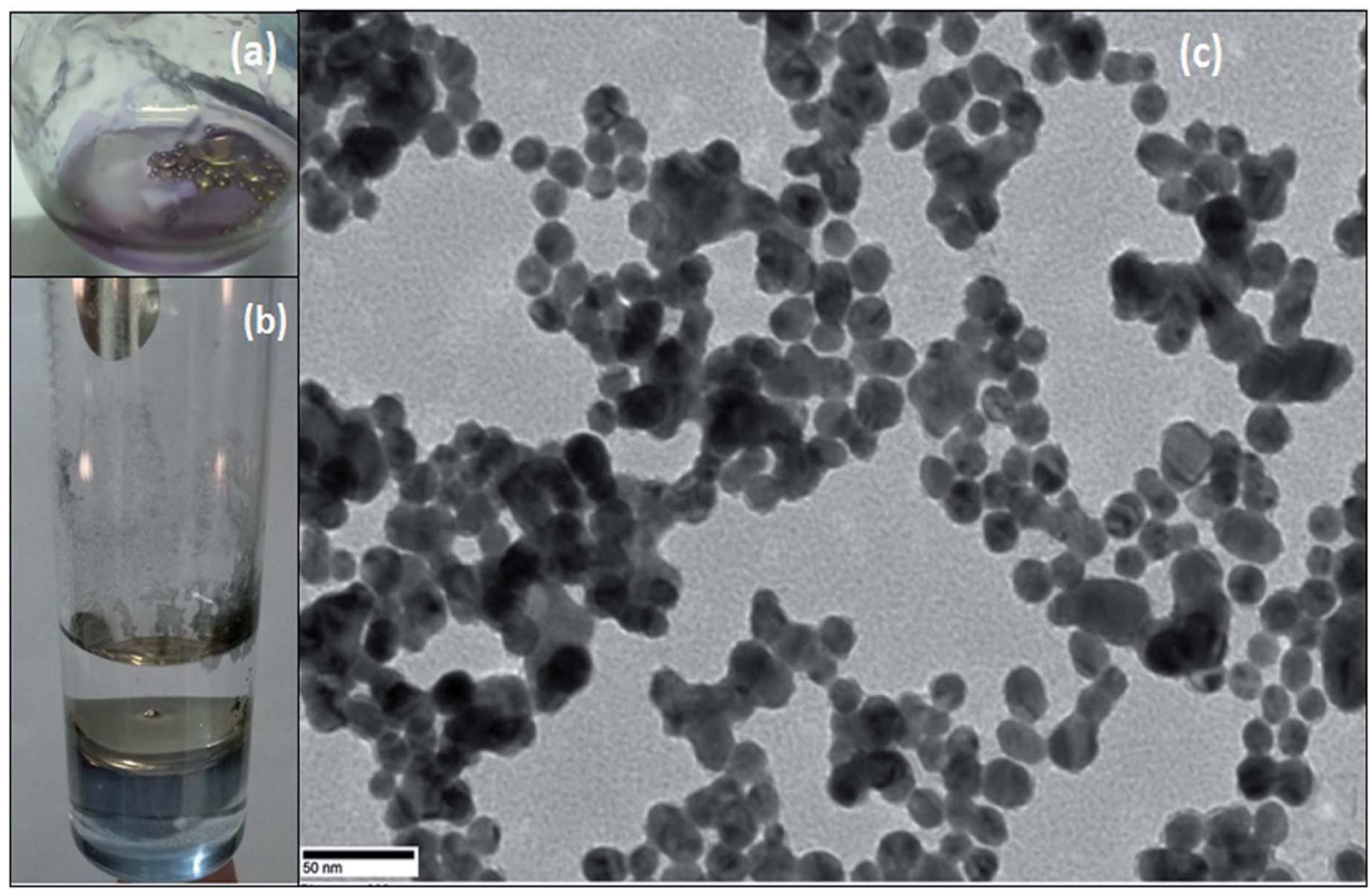

Fig. 2 Images of AuNPs (a) stabilized on water droplets (b) sheet like structure at water-chloroform interface, (c) TEM image of AuNPs obtained from (a).

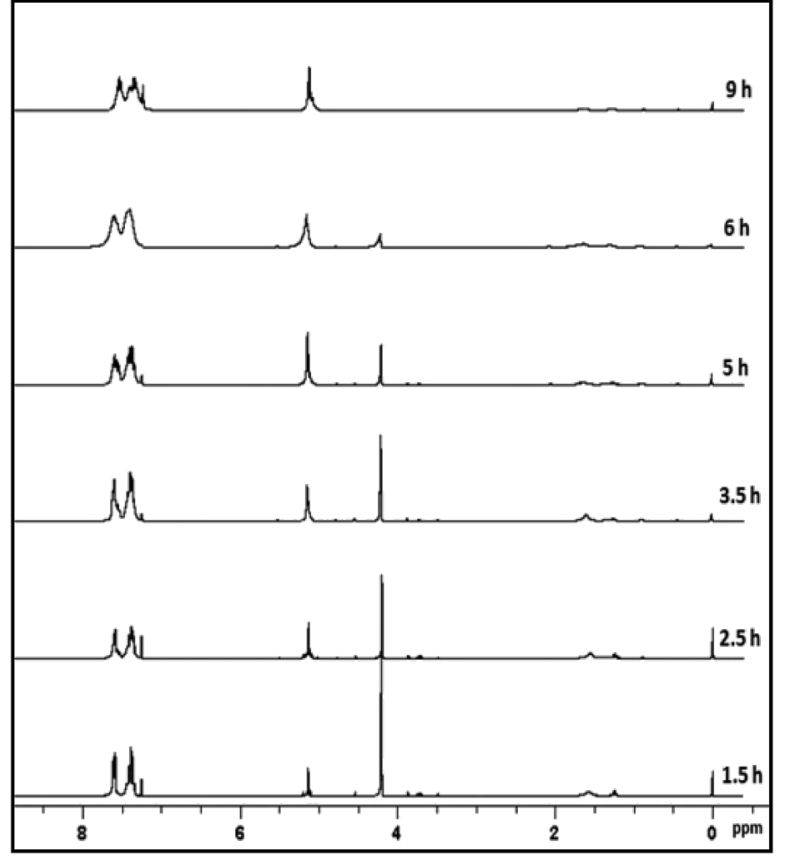

Fig. $3{ }^{1} \mathrm{H}$ NMR spectra at different time intervals during hydrolytic oxidation of phenylsilane.

polymer. The IR spectrum exhibits characteristic absorption at $2173 \mathrm{~cm}^{-1}$ due to Si-H groups. The ${ }^{29} \mathrm{Si}$ NMR spectrum (Fig. 4) identifies two distinct regions of chemical shifts at $\delta-44$ to

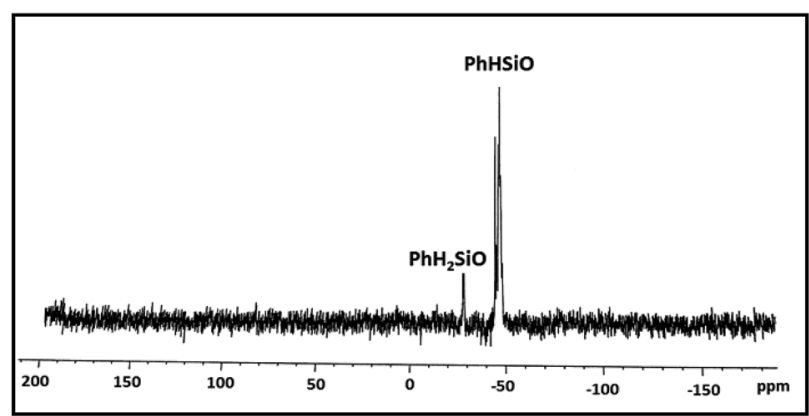

Fig. $4{ }^{29} \mathrm{Si}\left\{{ }^{1} \mathrm{H}\right\}$ NMR spectrum of poly(hydrophenylsiloxane), 2.

-47 and -27.0 . The former value is assigned to $\mathrm{PhHSiO}$ units while the later to $\mathrm{H}_{2} \mathrm{PhSiO}$ end groups. Similar chemical shifts have been reported earlier for $\mathrm{H}_{2} \mathrm{PhSiOSiPhH}_{2}\left(\delta-27, \mathrm{t},{ }^{1} \mathrm{~J}_{\mathrm{Si}-\mathrm{H}}\right.$ $=224 \mathrm{~Hz})$ and $\left[\mathrm{PhHSiO}_{n}\left(\delta-46.8, d,{ }^{1} \mathrm{~J}_{\mathrm{Si}-\mathrm{H}}=259 \mathrm{~Hz}\right)\right.$ which has been prepared by controlled hydrolysis of $\mathrm{PhHSiCl}_{2} \cdot{ }^{18}$ Thermo gravimetric analysis (TGA) and differential scanning calorimetric (DSC) study of 2 reveal that the polymer is thermally stable upto $280{ }^{\circ} \mathrm{C}$ and exhibits the glass transition temperature $\left(T_{\mathrm{g}}\right.$ ) at $-59{ }^{\circ} \mathrm{C}$ (Fig. S7 $\dagger$ ). Interestingly, $T_{\mathrm{g}}$ is markedly higher than that of poly(hydromethylsiloxane) $\left(T_{\mathrm{g}}=\right.$ $-138{ }^{\circ} \mathrm{C}$ ) suggesting a reduced flexibility of the siloxane backbone. ${ }^{19}$ It is pertinent to mention that the blank experiments in the absence of [Au] catalyst and water separately do not proceed at all and the substrate is recovered unchanged after $24 \mathrm{~h}$. 


\section{Synthesis and characterization of poly(alkylhydrosiloxane)s, 3-6}

To expand the substrate scope, the Pickering catalyst, [Au] has been further examined for the hydrolytic oxidation of primary alkylsilanes, $\mathrm{RSiH}_{3}\left[\mathrm{R}=n\right.$-hexyl, cyclo-hexyl, $\mathrm{Et}_{3} \mathrm{SiCH}_{2} \mathrm{CH}_{2}$, $\mathrm{PhMe}_{2} \mathrm{SiCH}_{2} \mathrm{CH}_{2}$ ] under conditions similar to those described above for phenylsilane. An illustrative ${ }^{1} \mathrm{H}$ NMR spectra showing the progress of the reaction for $n$-hexylsilane as the precursor is given in ESI (Fig. S8) $\uparrow$ A complete consumption of the organosilane in each case is observed within 10-12 h. The corresponding poly(hydrosiloxane)s, $\mathrm{H}_{2} \mathrm{RSiO}[\mathrm{RHSiO}]_{n} \mathrm{SiRH}_{2}$ 3-6 were isolated as viscous oils and characterized by GPC, IR, ${ }^{1} \mathrm{H}$ and ${ }^{29} \mathrm{Si}$ NMR spectroscopy. These are thermally stable upto $200{ }^{\circ} \mathrm{C}$ (Fig. S9 $\dagger$ ) and thermal stability decreases in the order: cyclohexyl $>n$-hexyl $>\mathrm{Et}_{3} \mathrm{SiCH}_{2} \mathrm{CH}_{2} \approx \mathrm{PhMe}_{2} \mathrm{SiCH}_{2} \mathrm{CH}_{2}$. The GPC profiles of 3-6 shown in Fig. 5 reveal molecular weight $\left(M_{\mathrm{w}}\right)$ in the range of $1.1-1.8 \times 10^{3}$ (PDI $\left.=1.2-1.4\right)$ suggesting that the polymerization rate is comparable to that of phenylsilane. The ${ }^{1} \mathrm{H}$ NMR spectra exhibit characteristic signals at $\delta$ 4.4-4.6 and 0.6-1.9 due to $\mathrm{Si}-H$ and alkyl groups respectively in $1: 1$ integral ratio suggesting the presence of $\mathrm{RHSiO}$ repeat units. Additional evidence with regard to the composition of these polymers comes from characteristic ${ }^{29} \mathrm{Si}$ NMR signals at $\delta-32$ to -37 and -17 to -19 (Fig. S10 $\dagger$ ) which are attributed to RHSiO and $\mathrm{H}_{2} \mathrm{RSiO}$ units respectively by comparison with those reported earlier for [RHSiO $]_{n}$ and $\mathrm{H}_{2} \mathrm{RSiOSiRH}_{2}\left(\mathrm{R}=\right.$ octadecyl). ${ }^{20}$ The IR absorptions due to $\mathrm{Si}-\mathrm{H}, \mathrm{Si}-\mathrm{O}$ and aliphatic groups appear at $2140-2160,1050-1070$ and $2900-3000 \mathrm{~cm}^{-1}$ respectively.

The efficiency of the Pickering catalyst after the first cycle of the reaction decreases as evident from a longer reaction time (18-24 h) for complete hydrolytic oxidation of organosilanes. To understand this phenomenon, the AuNPs were examined after the first cycle by HRTEM (Fig. S11 $\dagger$ ). The micrograph reveals that structural reorganization of the primitive nanoparticles occurs during the catalytic event at elevated temperature and

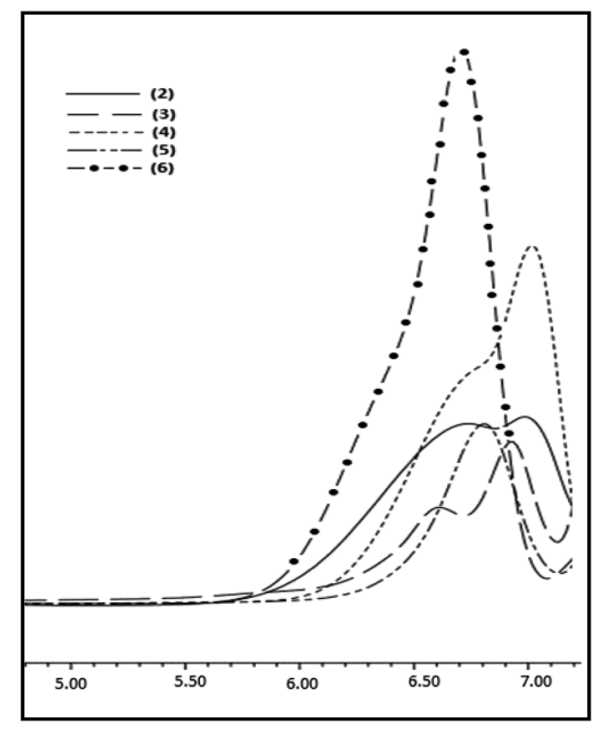

Fig. 5 GPC profiles of the polymers 2-6.

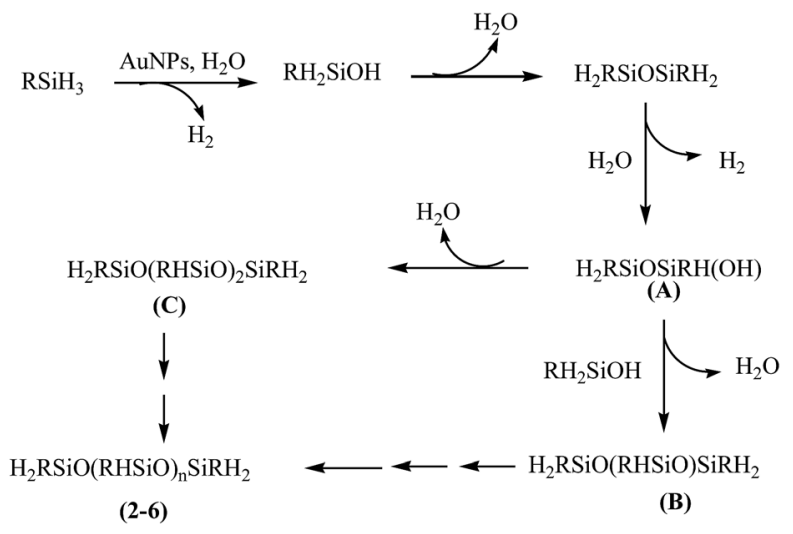

Scheme 2 Proposed catalytic pathway for the synthesis of 2-6.

aggregation of individual nanoparticles is discernable in the TEM image. The plasmonic band appears at $570 \mathrm{~nm}$ and undergoes a bathochromic shift of the order of $30 \mathrm{~nm}$ as compared to primitive AuNPs. Such modulations in the catalytic cycles have been previously observed in PdNPs during Suzuki coupling reaction between phenyl boronic acid and iodobenzene. ${ }^{21}$

There has been ample precedence in literature which provides a mechanistic rationale for the oxidation of organosilanes using AuNP catalyst. It has been suggested that the reaction proceeds via the formation of $\mathrm{Au}-\mathrm{H}$ and $\mathrm{Au}-\mathrm{Si}$ bonds and subsequent reaction of these species with water affords the formation of silanol with the elimination of dihydrogen. ${ }^{22} \mathrm{~A}$ similar pathway (Scheme 2) has been proposed in the present study to explain the catalytic activity of [Au] and formation of poly(alkyl/arylhydrosiloxane)s 2-6. The identity of $\mathbf{A}$ to $\mathbf{C}$ formed as intermediates is authenticated by GC-MS spectral studies (vide supra). An added evidence in favour of the selectivity of the [Au] catalyst comes from the catalytic oxidation of diphenylsilane which affords $\mathrm{HPh}_{2} \mathrm{SiOSiPh}_{2} \mathrm{H}(7)$ within $2 \mathrm{~h}$ in $>99 \%$ yield.

The results provide a basis to infer that the $\mathrm{Si}-\mathrm{H}$ groups directly bonded to a siloxy unit is far less prone to oxidation under the reaction conditions employed. To our knowledge, there have been only a few reports on the AuNP-catalyzed hydrolytic oxidation of primary organosilanes. In a related study, the alkylsilane, $\mathrm{C}_{18} \mathrm{H}_{37} \mathrm{SiH}_{3}$ is known to undergo complete oxidation of the $\mathrm{Si}-\mathrm{H}$ groups and affords the formation of nanowire-like structures build up from $\mathrm{RSiO}_{1.5}$ units. ${ }^{23}$

\section{Conclusions}

We have demonstrated that surface decoration of AuNPs with amphiphilic block copolymer $\mathbf{1}$ assists the organization of the nanoparticles at water-chloroform interface. The interfacial stabilization of AuNPs provides a platform to study their catalytic activity and selectivity for hydrolytic oxidation of primary alkyl/aryl silanes. This has resulted in the development of a versatile approach for the synthesis of poly(alkyl/ arylhydrosiloxane)s, 2-6 bearing [RHSiO] repeat units. Further studies are in progress to expand the scope of these poly(hydrosiloxane)s to incorporate new functional groups and explore their possible applications. 


\section{Experimental}

\section{Materials and methods}

Solvents were freshly distilled over sodium wire/benzophenone (tetrahydrofuran, toluene) under inert atmosphere. Chloroform (Fischer, HPLC grade) was used as received. Glassware were dried in an oven at $110-120{ }^{\circ} \mathrm{C}$ and further flame dried under vacuum prior to use. Triethylamine was dried over potassium hydroxide and distilled before use. Copper(I) bromide (Sigma Aldrich) was stirred in glacial acetic acid overnight, filtered and washed with absolute ethanol under nitrogen atmosphere. Isobornyl acrylate (iBA) was passed through alumina column to remove the inhibitor. The polymer, bis(hydroxyethoxypropyl)terminated PDMS $\left(M_{\mathrm{n}}=5600 \mathrm{~g} \mathrm{~mol}^{-1}\right)$, 2-bromoisobutyryl bromide and $N, N, N^{\prime}, N^{\prime \prime}, N^{\prime \prime}$-pentamethyldiethylenetriamine (PMDETA), phenylsilane, $n$-hexylsilane, cyclo-hexylsilane, triethylsilane and lithium aluminium hydride were purchased from Sigma Aldrich and used as procured. ${ }^{1} \mathrm{H},{ }^{13} \mathrm{C}$ and ${ }^{29} \mathrm{Si} \mathrm{NMR}$ spectra were recorded in $\mathrm{CDCl}_{3}$ on Bruker AVANCE II $400 \mathrm{NMR}$ spectrometer and the chemical shifts are quoted relative to $\mathrm{Me}_{4} \mathrm{Si}$. IR spectra were recorded on Nicolet protege 460 ESP spectrometer using $\mathrm{KBr}$ optics. UV-Vis spectral studies were performed on Perkin-Elmer (Lambda Bio 20) spectrophotometer. Transmission electron microscopic (TEM) studies were carried out using carbon coated copper grid on a Philips CM 20 electron microscope operated at $100 \mathrm{kV}$. Molecular weight $\left(M_{\mathrm{w}}\right)$ and polydispersity index (PDI) of the polymers were estimated using Waters gel permeation chromatography (GPC) equipped with L-2414 refractive index detector and Waters styragel HR3 and HR4 columns in series using THF as eluent (flow rate $1 \mathrm{~mL}$ $\min ^{-1}$; polystyrene standards). Thermo gravimetric analysis (TGA) and differential scanning calorimetry (DSC) measurements were carried out in nitrogen atmosphere at a heating rate $10{ }^{\circ} \mathrm{C} \mathrm{min}^{-1}$ on a Perkin Elmer Thermal analysis system.

\section{Synthetic methods}

The organosilanes, $\mathrm{RSiH}_{3}\left(\mathrm{R}=\mathrm{Et}_{3} \mathrm{SiCH}_{2} \mathrm{CH}_{2}, \mathrm{PhMe}_{2} \mathrm{SiCH}_{2} \mathrm{CH}_{2}\right)$ were synthesized according to the procedure reported earlier. ${ }^{24}$ The difunctional macroinitiator (Br-PDMS-Br) was prepared by following the procedure reported earlier, ${ }^{25}$ using bis(hydroxyethoxypropyl) terminated PDMS $(5.0 \mathrm{~g}, 1.0 \mathrm{mmol})$, triethylamine $(0.63 \mathrm{~g}, 6.0 \mathrm{mmol})$ and 2-bromoisobutyryl bromide $(0.69 \mathrm{~g}, 3.0 \mathrm{mmol})$ as the starting materials. The IR, ${ }^{1} \mathrm{H},{ }^{13} \mathrm{C}$ and ${ }^{29} \mathrm{Si}$ NMR data of the macroinitiator are summarized below.

${ }^{1} \mathrm{H}$ NMR $\left(\mathrm{CDCl}_{3}\right): \delta 0.07\left(\mathrm{br}, \mathrm{SiCH}_{3}\right), 0.57\left(\mathrm{br}, \mathrm{SiCH}_{2}\right), 1.57$ (br, $\left.\mathrm{SiCH}_{2} \mathrm{CH}_{2}\right), 1.95$ [br, $\mathrm{BrC}\left(\mathrm{CH}_{3}\right)_{2}$ ], 3.45 (br, $\left.\mathrm{SiCH}_{2} \mathrm{CH}_{2} \mathrm{CH}_{2}\right), 3.67$ (br, $\mathrm{OCH}_{2}$ ), 4.32 (br, $\left.\mathrm{CH}_{2} \mathrm{OC}=\mathrm{O}\right) ;{ }^{13} \mathrm{C}\left\{{ }^{1} \mathrm{H}\right\} \mathrm{NMR}\left(\mathrm{CDCl}_{3}\right): \delta 1.0$ $\left(\mathrm{SiCH}_{3}\right), 14.1\left(\mathrm{SiCH}_{2}\right), 23.4\left(\mathrm{SiCH}_{2} \mathrm{CH}_{2}\right), 30.7\left[\mathrm{BrC}\left(\mathrm{CH}_{3}\right)_{2}\right], 65.2$ $\left(\mathrm{SiCH}_{2} \mathrm{CH}_{2} \mathrm{CH}_{2}\right), 68.1\left(\mathrm{OCH}_{2}\right), 74.1\left(\mathrm{CH}_{2} \mathrm{OC}=\mathrm{O}\right), 175.2(\mathrm{C}=\mathrm{O})$; ${ }^{29} \mathrm{Si} \mathrm{NMR}\left(\mathrm{CDCl}_{3}, \delta\right):-21.9$. IR $\left(\mathrm{KBr}, \mathrm{cm}^{-1}\right): 1089\left(\nu_{\mathrm{Si}-\mathrm{O}-\mathrm{Si}}\right), 1260$ $\left(\nu_{\mathrm{Si}_{-} \mathrm{CH}_{3}}\right), 1742\left(\nu_{\mathrm{C}=\mathrm{O}}\right)$.

\section{Synthesis of PiBA $_{20}-b-P^{-} M_{75}-b-P_{1 B A}, 1$}

In a typical procedure, the macroinitiator, Br-PDMS-Br $(1.0 \mathrm{~g}$, $0.17 \mathrm{mmol}$ ), iBA (3.4 g, $17.0 \mathrm{mmol})$ and $\mathrm{CuBr}(0.048 \mathrm{~g}, 0.34$ $\mathrm{mmol})$ in dry toluene $(2.0 \mathrm{~mL})$ were introduced into a two-neck round bottom flask equipped with a magnetic stirrer. The contents were subjected to three freeze-pump-thaw cycles to remove oxygen and $N, N, N^{\prime}, N^{\prime \prime}, N^{\prime \prime}$-pentamethyldiethylenetriamine (PMDETA) (0.12 g, $0.68 \mathrm{mmol}$ ) was added while keeping the reaction mixture at $80{ }^{\circ} \mathrm{C}$. The reaction was allowed to continue for 4-5 $\mathrm{h}$ and the content thereafter was dissolved in THF and passed through neutral alumina column to remove the copper catalyst. The polymer $\mathbf{1}$ was isolated as a white solid by repeated precipitation in methanol. The numerical notations for the assignment of various protons are shown in Scheme 1.

${ }^{1} \mathrm{H}$ NMR $\left(\mathrm{CDCl}_{3}\right): \delta 0.06\left(\mathrm{H} 1, \mathrm{Si}-\mathrm{CH}_{3}\right), 0.57\left(\mathrm{H}_{2}, \mathrm{SiCH}_{2}\right), 0.80-$ 1.70 [H10-H11, H13-H20 (isobornyl ring) + H3, $\left.\mathrm{SiCH}_{2} \mathrm{CH}_{2}\right], 2.27$ [H9, C(O)CH], $3.45\left(\mathrm{H} 4, \mathrm{SiCH}_{2} \mathrm{CH}_{2} \mathrm{CH}_{2}\right), 3.67\left(\mathrm{H} 5, \mathrm{OCH}_{2}\right), 4.25$ (H6, $\left.\mathrm{CH}_{2} \mathrm{OC}=\mathrm{O}\right), 4.32$ (H12, $\mathrm{CH}$-isobornyl). IR $\left(\mathrm{KBr}, \mathrm{cm}^{-1}\right) 1089$ $\left(\nu_{\mathrm{Si}-\mathrm{O}-\mathrm{Si}}\right), 1260\left(\nu_{\mathrm{Si}_{-} \mathrm{CH}_{3}}\right), 1727\left(\nu_{\mathrm{C}=\mathrm{O}}\right) \cdot{ }^{29} \mathrm{Si} \mathrm{NMR}\left(\mathrm{CDCl}_{3}\right): \delta-21.9$.

\section{Synthesis of Pickering interfacial catalyst (PIC)}

To a solution containing hydrogen tetrachloroaurate(III) trihydrate $(10.0 \mathrm{mg}, 0.025 \mathrm{mmol}$ ) in chloroform (20.0 mL, HPLC), a solution of polymer $1,(10.0 \mathrm{mg}, 0.04 \mathrm{mmol}$ with respect to polymer repeat unit) in the same solvent $(5.0 \mathrm{~mL})$ was added under sonication. Thereafter, triethylsilane $(10 \mu \mathrm{L}, 0.1 \mathrm{mmol})$ was added and the resulting solution was kept for $24 \mathrm{~h}$ at room temperature and subsequently used for analysis. The above solution of AuNPs $(4.0 \mathrm{~mL})$ was taken separately and mixed with $1.0 \mathrm{~mL}$ of deionized water with constant stirring to obtain AuNP-stabilized water droplets in chloroform medium and used for catalytic reactions.

\section{Synthesis of poly(aryl/alkyl)hydrosiloxanes, 2-6}

In a typical procedure, hydrolytic oxidation of primary organosilanes, $\mathrm{RSiH}_{3}(2.0 \mathrm{~mL}, 0.02 \mathrm{mmol})$ was performed in the presence of Au-stabilized PIC under aerobic conditions at $80^{\circ} \mathrm{C}$. After complete consumption of the monomer, the organic layer was separated and dried over sodium sulphate. The solvent was evaporated under vacuum and poly(hydrosiloxane)s, 2-6 were isolated as viscous oils.

$\mathbf{H}_{2} \mathrm{PhSiO}[\mathrm{PhHSiO}]_{n} \mathrm{SiPhH}_{2}, 2 .{ }^{1} \mathrm{H}$ NMR $\left(\mathrm{CDCl}_{3}\right): \delta 7.24(\mathrm{br}$, $5 \mathrm{H}, \mathrm{Si} P h), 5.14$ (br, $1 \mathrm{H}, \mathrm{Si}-H) ;{ }^{29} \mathrm{Si}\left\{{ }^{1} \mathrm{H}\right\} \mathrm{NMR}\left(\mathrm{CDCl}_{3}\right): \delta-27.0$ $\left[\mathrm{H}_{2} \mathrm{PhSiO}\right],-44$ to $-47(\mathrm{HPhSiO}) ; \mathrm{IR}\left(\mathrm{KBr}, \mathrm{cm}^{-1}\right) ; 3070,3052$ $\left(\nu_{\mathrm{C}-\mathrm{H}}\right.$, aromatic $), 2173\left(\nu_{\mathrm{Si}-\mathrm{H}}\right), 1429\left(\delta_{\mathrm{C}-\mathrm{H}}\right), 1085\left(\nu_{\mathrm{Si}-\mathrm{O}-\mathrm{Si}}\right) \cdot M_{\mathrm{w}}=$ $1.5 \times 10^{3}, \mathrm{PDI}=1.4$.

$\mathbf{H}_{2}$ (n-hexyl)SiO $\left[(n \text {-hexyl)HSiO }]_{n} \operatorname{Si}\left(n\right.\right.$-hexyl)H $H_{2}, \quad 3 .{ }^{1} \mathrm{H} \quad \mathrm{NMR}$ $\left(\mathrm{CDCl}_{3}\right): \delta 0.54\left(\mathrm{br}, 2 \mathrm{H}, \mathrm{Si}-\mathrm{CH}_{2}\right), 0.67-0.79\left(\mathrm{br}, 4 \mathrm{H}, \mathrm{CH}_{2}\right), 1.2(\mathrm{br}$, $9 \mathrm{H}), 4.56(\mathrm{br}, 1 \mathrm{H}, \mathrm{Si}-H) ;{ }^{29} \mathrm{Si}\left\{{ }^{1} \mathrm{H}\right\} \mathrm{NMR}\left(\mathrm{CDCl}_{3}\right): \delta-20.0\left(\mathrm{H}_{2} \mathrm{SiO}\right)$, -33.2, -34.71, -35.89 (HSiO); IR ( $\left.\mathrm{KBr} \mathrm{cm}^{-1}\right): 2957,2924\left(\nu_{\mathrm{C}-\mathrm{H}}\right.$, aliphatic), $2160\left(\nu_{\mathrm{Si}-\mathrm{H}}\right), 1461\left(\delta_{\mathrm{C}-\mathrm{H}}\right), 1089\left(\nu_{\mathrm{Si}-\mathrm{O}-\mathrm{Si}}\right) . M_{\mathrm{w}}=1.2 \times$ $10^{3}$, PDI $=1.2$.

$\mathbf{H}_{2}$ (cyclo-hexyl)SiO $\left[(\text { cyclo-hexyl)(H)SiO }]_{n} \mathrm{Si}\left(\right.\right.$ cyclo-hexyl) $\mathrm{H}_{2}, 4$. ${ }^{1} \mathrm{H} \mathrm{NMR}\left(\mathrm{CDCl}_{3}\right): \delta 0.54$ (br, $\left.1 \mathrm{H}, \mathrm{Si}-\mathrm{CH}\right), 1.37$ (br, 4H, $\left.\mathrm{CH}_{2}\right), 1.9$ (br, 6H), $4.42(1 \mathrm{H}, \mathrm{Si}-H) ;{ }^{29} \mathrm{Si}\left\{{ }^{1} \mathrm{H}\right\}$ NMR $\left(\mathrm{CDCl}_{3}\right): \delta-17.6\left(\mathrm{H}_{2} \mathrm{SiO}\right)$, -33.17, -35.92, -37.09 (HSiO); IR ( $\left.\mathrm{KBr} \mathrm{cm}^{-1}\right): 2957,2924\left(\nu_{\mathrm{C}-\mathrm{H}}\right.$, aliphatic), $2160\left(\nu_{\mathrm{Si}-\mathrm{H}}\right), 1461\left(\delta_{\mathrm{C}-\mathrm{H}}\right), 1085\left(\nu_{\mathrm{Si}-\mathrm{O}-\mathrm{Si}}\right) . M_{\mathrm{w}}=1.1 \times$ $10^{3}$, PDI $=1.4$.

$\mathbf{H}_{2} \mathrm{RSiO}[\mathrm{RHSiO}]_{n} \mathrm{SiRH}_{2}\left(\mathrm{R}=\mathbf{E t}_{3} \mathrm{SiCH}_{2} \mathbf{C H}_{2}\right)$, 5. ${ }^{1} \mathrm{H} \quad \mathrm{NMR}$ $\left(\mathrm{CDCl}_{3}\right): \delta 0.54\left(\mathrm{br}, 8 \mathrm{H}, \mathrm{SiCH}_{2}\right), 1.12\left(\mathrm{br}, 11 \mathrm{H}, \mathrm{SiCH}_{2} \mathrm{CH}_{2}, \mathrm{CH}_{3}\right.$ ), 
$4.66(\mathrm{Si}-H) ;{ }^{29} \mathrm{Si}\left\{{ }^{1} \mathrm{H}\right\} \quad \mathrm{NMR}: \delta \quad 8.63,8.40 \quad\left\{\left(\mathrm{C}_{2} \mathrm{H}_{5}\right)_{3} \mathrm{Si}\right\},-19.2$ $\left(\mathrm{H}_{2} \mathrm{SiO}\right),-32.2,-34.5$ ( $\left.\mathrm{HSiO}\right)$; IR $\left(\mathrm{KBr}, \mathrm{cm}^{-1}\right): 2953,2908\left(\nu_{\mathrm{C}-\mathrm{H}}\right.$, aromatic), $2140\left(\nu_{\mathrm{Si}-\mathrm{H}}\right), 1414\left(\delta_{\mathrm{C}-\mathrm{H}}\right), 1075\left(\nu_{\mathrm{Si}-\mathrm{O}-\mathrm{Si}}\right) \cdot M_{\mathrm{w}}=1.1 \times$ $10^{3}$, PDI $=1.1$.

$\mathrm{H}_{2} \mathrm{RSiO}[\mathrm{RHSiO}]_{n} \mathrm{SiRH}_{2}\left(\mathrm{R}=\mathrm{PhMe}_{2} \mathrm{SiCH}_{2} \mathrm{CH}_{2}\right)$, 6. ${ }^{1} \mathrm{H}$ NMR $\left(\mathrm{CDCl}_{3}\right): \delta$ 0.50-0.64 (br, 8H, SiMe, $\left.\mathrm{SiCH}_{2}\right), 1.02(\mathrm{br}, 2 \mathrm{H}$, $\mathrm{SiCH}_{2} \mathrm{CH}_{2}$ ), 4.58 (br, Si-H), 7.24 (br, 5H, SiPh); ${ }^{29} \mathrm{Si}\left\{{ }^{1} \mathrm{H}\right\}$ NMR $\left(\mathrm{CDCl}_{3}\right): \delta-5.36\left(\mathrm{Ph}_{2} \mathrm{MeSi}\right),-34.96(\mathrm{HSiO}) ; \mathrm{IR}\left(\mathrm{KBr}, \mathrm{cm}^{-1}\right)$ : 3070, $3052\left(\nu_{\mathrm{C}-\mathrm{H}}\right.$, aromatic), $2150\left(\nu_{\mathrm{Si}-\mathrm{H}}\right), 1421\left(\delta_{\mathrm{C}-\mathrm{H}}\right), 1081$ $\left(\nu_{\mathrm{Si}-\mathrm{O}-\mathrm{Si}}\right) \cdot M_{\mathrm{w}}=1.8 \times 10^{3}$, PDI $=1.3$.

$\left[\mathrm{Ph}_{2}(\mathrm{H}) \mathrm{Si}\right]_{2} \mathrm{O}$ [product from $\left.\mathrm{Ph}_{2} \mathrm{SiH}_{2}\right], 7 .{ }^{1} \mathrm{H} \mathrm{NMR}\left(\mathrm{CDCl}_{3}, \delta\right)$ : 7.63, 7.31, (m, 20H, Si-Ph), 5.59 (s, 2H, Si-H); ${ }^{29} \mathrm{Si}\left\{{ }^{1} \mathrm{H}\right\}$ NMR $\left(\mathrm{CDCl}_{3}, \delta\right):-19.8 . \mathrm{IR}\left(\mathrm{KBr}, \mathrm{cm}^{-1}\right): 3062,3011\left(\nu_{\mathrm{C}-\mathrm{H}}\right.$, aromatic), $2135\left(\nu_{\mathrm{Si}-\mathrm{H}}\right), 1428\left(\delta_{\mathrm{C}-\mathrm{H}}\right), 1067\left(\nu_{\mathrm{Si}-\mathrm{O}-\mathrm{Si}}\right)$; GC-MS: retention time $\left(t_{\mathrm{R}}\right)=31.5 \mathrm{~min}, \mathrm{~m} / \mathrm{z}$ calcd, 382 ; found, 382 .

\section{Acknowledgements}

We thank UGC (India) for a fellowship to Bhawana and Department of Physics, IIT Delhi for TEM studies. This research was supported by financial grant (Project No. SB/S3/EECE/095/ 2014) from DST (India).

\section{Notes and references}

1 (a) J. E. Mark, R. West and H. R. Allcock, Inorganic Polymers, Prentice-Hall, Englewood Cliffs, 1992; (b) M. A. Brook, Silicon in Organic Organometallic and Polymer chemistry, John Willey \& Sons, New York, 2000, pp. 256-308; (c) J. E. Mark, Acc. Chem. Res., 2004, 37, 946; (d) P. Zheng and T. J. McCarthy, Langmuir, 2010, 26, 18585.

2 Y. Abe and T. Gunji, Prog. Polym. Sci., 2004, 29, 149.

3 (a) J. Chojnowski, in Siloxane Polymer, ed. S. Clarson and J. Semlyen, PTR Prentice Hall, London, 1993, p. 1; (b) W. P. Weber and G. Cai, Macromolecules, 2001, 34, 4355; (c) A. Molenberg and M. Moller, Macromol. Rapid Commun., 1995, 16, 449; (d) K. Rózga-Wijas, J. Chojnowski, T. Zundel and S. Boileau, Macromolecules, 1996, 29, 2711; (e) E. Pouget, J. Tonnar, P. Lucas, P. Lacroix-Desmazes, F. Ganachaud and B. Boutevin, Chem. Rev., 2010, 110, 1233.

4 (a) K. Kuroda, A. Shimojima, K. Kawahara, R. Wakabayashi, Y. Tamura, Y. Asakura and M. Kitahara, Chem. Mater., 2014, 26, 211; (b) R. Wakabayashi and K. Kuroda, ChemPlusChem, 2013, 78, 764; (c) R. Wakabayashi, K. Kawahara and K. Kuroda, Angew. Chem., Int. Ed., 2010, 49, 5273; (d) J. B. Grande, F. Gonzaga and M. A. Brook, Dalton Trans., 2010, 39, 9369; (e) D. B. Thompson and M. A. Brook, J. Am. Chem. Soc., 2008, 130, 32; (f) G. Hreczycho, P. Pawluc and B. Marciniec, New J. Chem., 2011, 35, 2743; (g) R. Zhang, J. E. Mark and A. R. Pinhas, Macromolecules, 2000, 33, 3508; (h) W. Xue, M. C. Kung and H. H. Kung, Chem. Commun., 2005, 2164; (i) Z. Chang, M. C. Kung and H. H. Kung, Chem. Commun., 2004, 206.

5 (a) G. H. Barnes and N. E. Daughenbaugh, J. Organomet. Chem., 1966, 31, 885; (b) Y. Lee, D. Seomoon, S. Kim, H. Han, S. Chang and P. H. Lee, J. Org. Chem., 2004, 69, 1741; (c) R. A. Corbin, E. A. Ison and M. M. Abu-Omar,
Dalton Trans., 2009, 2850; (d) T. C. Bedard and J. Y. Corey, J. Organomet. Chem., 1992, 428, 315; (e) E. A. Ison, R. A. Corbin and M. M. Abu-Omar, J. Am. Chem. Soc., 2005, 127, 11938.

6 (a) T. Mitsudome, S. Arita, H. Mori, T. Mizugaki, K. Jitsukawa and K. Kaneda, Angew. Chem., Int. Ed., 2008, 47, 7938; (b) N. Asao, Y. Ishikawa, N. Hatakeyama, Menggenbateer, Y. Yamamoto, M. Chen, W. Zhang and A. Inoue, Angew. Chem., Int. Ed., 2010, 49, 10093; (c) T. Mitsudome, A. Noujima, T. Mizugaki, K. Jitsukawaa and K. Kaneda, Chem. Commun., 2009, 5302; (d) M. Jeon, J. Han and J. Park, ACS Catal., 2012, 2, 1539.

7 S. Maisonnier, J.-C. Favier, M. Masure and P. Hemery, Polym. Int., 1999, 48, 159.

8 (a) F. Gonzaga, R. D'Souza and M. A. Brook, Soft Matter, 2011, 7, 722; (b) M. F. Dumont, S. Moisan, C. Aymonier, J.-D. Marty and C. Mingotaud, Macromolecules, 2009, 42, 4937; (c) B. P. S. Chauhan, J. S. Rathore, M. Chauhan and A. Krawicz, J. Am. Chem. Soc., 2003, 125, 2876; (d) R. Zhang, Z. Zhang, K. Amine and R. West, Silicon Chem., 2003, 2, 271; (e) Z. Zhang, L. J. Lyons, J. J. Jin, K. Amine and R. West, Chem. Mater., 2005, 17, 5646; $(f)$ N. A. A. Rossi, E. J. Duplock, J. Meegan, D. R. T. Roberts, J. J. Murphy, M. Patel and S. J. Holder, J. Mater. Chem., 2009, 19, 7674; (g) P. Zheng and T. J. McCarthy, J. Am. Chem. Soc., 2012, 134, 2024; (h) N. Roy, E. Buhler and J.-M. Lehn, Chem.-Eur. J., 2013, 19, 8814 .

9 (a) N. J. Lawrence, M. D. Drew and S. M. Bushell, J. Chem. Soc., Perkin Trans. 1, 1999, 1, 3381; (b) B. P. S. Chauhan and J. S. Rathore, J. Am. Chem. Soc., 2005, 127, 5790; (c) J. P. Patel, A.-H. Li, H. Dong, V. L. Korlipara and M. J. Mulvihill, Tetrahedron Lett., 2009, 50, 5975; (d) M. Giordano and A. Iadonisi, Eur. J. Inorg. Chem., 2013, 125; (e) R. J. Rahaim Jr and R. E. Maleczka Jr, Org. Lett., 2011, 13, 584; (f) B. P. S. Chauhan and R. Sardar, Macromolecules, 2004, 37, 5136.

10 (a) S. U. Pickering, J. Chem. Soc., 1907, 91, 2001; (b) C. N. R. Rao and K. P. Kalyanikutty, Acc. Chem. Res., 2008, 41, 489; (c) D. Wang, H. Duan and H. Möhwald, Soft Matter, 2005, 1, 412; (d) H. Duan, D. Wang, D. G. Kurth and H. Möhwald, Angew. Chem., Int. Ed., 2004, 43, 5639; (e) B. P. Binks, Curr. Opin. Colloid Interface Sci., 2002, 7, 21.

11 (a) M. Pera-Titus, L. Leclercq, J. -M. Clacens, F. De Campo and V. Nardello-Rataj, Angew. Chem., Int. Ed., 2014, 53, 2; (b) S. Crossley, J. Faria, M. Shen and D. E. Resasco, Science, 2010, 327, 68.

12 (a) C. Strissel, K. Matyjaszewski and O. Nuyken, Macromol. Chem. Phys., 2003, 204, 1169; (b) K. Matyjaszewski, Macromolecules, 2012, 45, 4015.

13 D. Khandelwal, S. Hooda and A. S. Brar, J. Mol. Struct., 2011, 991, 24.

14 R. A. Orwoll and P. A. Arnold, Physical Properties of Polymers Handbook, ed. J. E. Mark, AIP Press, New York, 1996.

15 I. M. Yu, P. Dubois and R. Jerome, Macromolecules, 1996, 29, 7316.

16 (a) A. Sugie, T. Somete, K. Kanie, A. Muramatsu and A. Mori, Chem. Commun., 2008, 3882; (b) R. Shankar, M. Chaudhary, 
K. C. Molloy and G. Kociok-Köhn, Dalton Trans., 2013, 42, 7768.

17 M. -C. Daniel and D. Astruc, Chem. Rev., 2004, 104, 293.

18 J. Moineau, M. Granier and G. F. Lanneau, Langmuir, 2004, 20, 3202.

19 J. C. Saam, J. Inorg. Organomet. Polym., 1999, 9, 1.

20 M. Granier, G. F. Lanneau, J. Moineau, P. Girard and M. Romanda, Langmuir, 2003, 19, 2691.
21 R. Narayanan and M. A. El-Sayed, J. Am. Chem. Soc., 2003, 125, 8340.

22 A. Marchenko, N. Katsonis, D. Fichou, C. Aubert and M. Malacria, J. Am. Chem. Soc., 2002, 124, 9998.

23 B. L. V. Prasad, S. I. Stoeva, C. M. Sorensen, V. Zaikovski and K. J. Klabunde, J. Am. Chem. Soc., 2003, 125, 10488.

24 R. Shankar, A. Saxena and A. S. Brar, J. Organomet. Chem., 2002, 650, 223.

25 R. Muppalla and S. K. Jewrajka, Polymer, 2012, 53, 1453. 